\title{
The calculus of the technical-economic parameters of a SI direct injection engine
}

\author{
T. Mitran*, V. Blaga, H. Beles, G. Dragomir \\ University of Oradea, Oradea, Romania \\ ${ }^{*}$ Corresponding author e-mail: tudor_mitran@yahoo.com \\ Article history \\ Received 10.07.2017 \\ Accepted 23.09.2017 \\ DOI https://doi.org/10.26825/bup.ar.2017.009
}

\begin{abstract}
The authors have proposed a model to simulate the processes that occur in a SI direct injection engine. The modelling of the engine's cycle consists of: the presentation of the initial data, the computer program, the calculus and the correlation between the expressions of the engine's parameters and the gasoline injection in order to realize the computational program. The proposed cycle is a helpful one for computer simulation of the gasoline direct injection. The computer simulation enables the determination of the proposed theoretical technical-economic parameters, the theoretical mechanical work, the coefficients corresponding to adjust the indicated diagram, the theoretical mean pressure, the theoretical efficiency and the theoretical specific fuel consumption. After calculating the mechanical losses, the effective theoretical technical-economic parameters are also determined.
\end{abstract}

\section{Introduction}

The gasoline direct injection was introduced in order to improve the engine's efficiency and to reduce the fuel consumption and the polluting emissions. The improvement of this type of engine can lead to superior performances and, especially, to the compliance with the severe environmental standards regarding the emissions.

In this paper the authors have proposed an original model to calculate: the parameters of the thermodynamic cycle, the mean indicated pressure and the efficiency of the engine.

This model can be used to study the SI direct injection engines and for adopting solutions that should lead to increase their performances. 


\section{The model of the direct injection SI Engine}

The engine for which the calculus was developed has the maximum effective power $\mathrm{P}=54 \mathrm{~kW}$, the cylinder's displacement $V_{s}=0,389 \mathrm{dm}^{3}$, the compression ratio $\varepsilon=9,25$, the bore $\mathrm{D}=77 \mathrm{~mm}$ and the piston's stroke $\mathrm{S}=83,6 \mathrm{~mm}$.

The model proposed by the authors is an original one because:

- the model of the injection system through which is realized the calculus of the pressure regulator, of the electromagnetic injector and the duration of the injection is original. This model includes two subprograms:

- one to calculate the parameters of the thermodynamic cycle depending on the rotational speed, on the environmental temperature and on the air excess coefficient, at the environmental temperature $\mathrm{p}_{0}=0,1 \mathrm{MPa}$;

- one to calculate the parameters of the thermodynamic cycle depending on the rotational speed and on the environmental temperature for an air excess coefficient $\lambda=1$, at the environmental temperature $\mathrm{p}_{0}=0,1 \mathrm{MPa}$;

- an own model was designed for the calculus of the pressure in the intake pipe and of the pressure at the end of the intake stroke;

Structurally, a gasoline injection system for an ICE represents a succession of energy conversions ( $\mathrm{C} 1$ to $\mathrm{C} 5$ in fig. ). In Figure 1: EM is the operating electric motor, FP is the fuel pump, RCE is the regulating and control equipment and SIE is the SI engine.

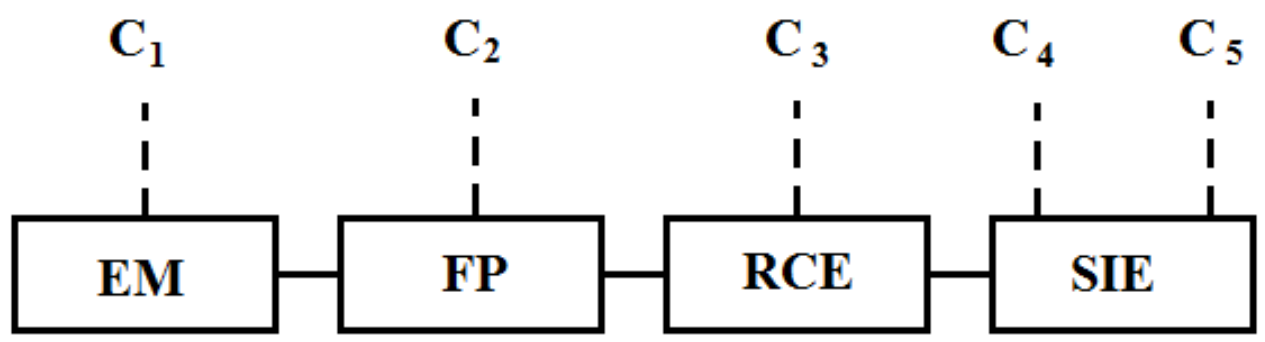

Figure 1. The scheme of the succession of energy conversion in an injection system

A series of laws, theorems, equations and basic relations from the theoretical mechanics, the fluid mechanics and mathematics are used to analyze and synthesize in dynamic regime the gasoline injection systems:

- from the theoretical mechanics:

- the fundamental laws of dynamics;

- the second Lagrange equation;

- the D'Alembert equation;

- from the fluid mechanics:

- the fluid's state equation;

- the characteristic equation;

- the law of viscose friction (Newton);

- the principle of mass conservation;

- the principle of energy conservation;

- the flow equation; 
- the Kirchoff law in the hydraulic knots;

Most systems of differential equations that describe the phenomena occurring in an injection system are nonlinear. The method used by the authors to solve the system of differential equations is the linear analyze on parts [1].

The thermodynamic cycle on which the calculus was based is presented in Figure. 2 .

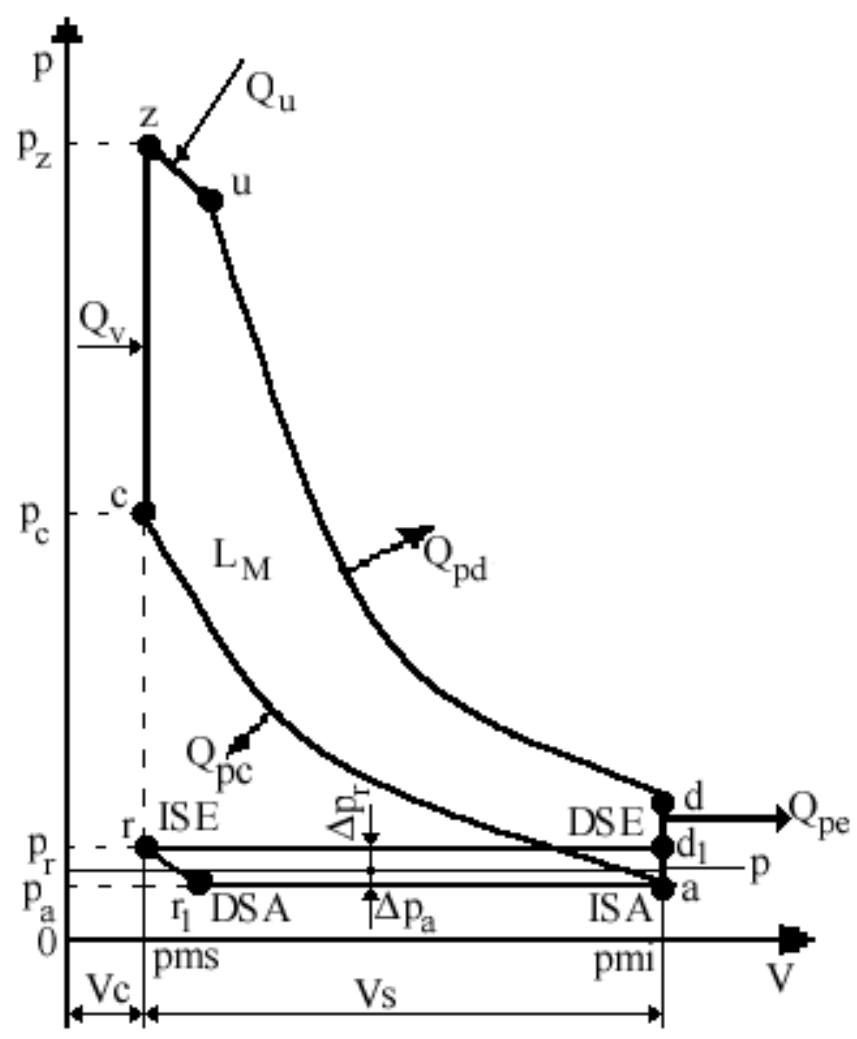

Figure 2. The thermodynamic cycle used for the calculus

The simplifying assumptions on which the thermodynamic cycle was defined are the following: - during the intake stroke $\left(r_{1}-a\right)$ the pressure remains constant at the value $p_{a}$, smaller than the environmental one $\mathrm{p}_{\mathrm{o}}$

- the exhaust process consists of two phases:

- one in which from the moment in which the exhaust valve opens the pressure drops sudden to the value $\mathrm{p}_{\mathrm{r}}$;

- one at constant pressure $\mathrm{p}_{\mathrm{r}}$ during the exhaust stroke;

- the link between the exhaust valve and the intake valve is made through an adiabatic expansion of the residual burned gases, with constant isentropic exponent $\left(r-r_{1}\right)$;

- the compression process (a-c) is considered to be a polytropic one, with constant exponent. During this process, the working fluid transfers the heat $\mathrm{Q}_{\mathrm{pc}}$ to the cylinder's walls.

- the burning process includes a constant volume phase $(\mathrm{c}-\mathrm{z})$ in which the heat input is $\mathrm{Q}_{\mathrm{v}}$ and the polytropic faze $(z-u)$ of exponent $n_{u}<1$, that defines the afterburning and in which the heat $Q_{u}$ is transferred to the working fluid;

- the expansion process $(\mathrm{u}-\mathrm{d})$ is considered to be a polytropic one, with constant exponent (greater than the adiabatic exponent), in which the working fluid transfers heat to the cylinder's walls;

- the thermal agent is considered to be an ideal gas, with specific heat depending on the temperature; 
The assimilation of the afterburning process with a polytropic one (with the sub unitary exponent $n_{u}$ ) is based on experimental data [2] showing that the temperature $T_{u}$ at the end of the burning process is greater than the temperature at the end of the constant volume burning phase $T_{z}$ as result of an intense heat release. This heat release should lead to an increase of the pressure. But the effect of the cylinder's instant volume increasing is greater so, during the afterburning, the pressure drops.

By modifying the exponent $n_{u}$ one can highlight on the influence of the heat release speed during the afterburning. On the other hand, one can use experimental data regarding the exponent $\mathrm{n}_{\mathrm{d}}$ of the expansion process that characterize the general expansion of the gases $(\mathrm{z}-\mathrm{u}-\mathrm{d})$. In other words, by combining the afterburning $(\mathrm{z}-\mathrm{u})$ with a sub unitary exponent $\mathrm{n}_{\mathrm{u}}$ with the actual expansion ( $\mathrm{u}-\mathrm{d}$ ) with exponent $\mathrm{n}_{\mathrm{d}}$ (greater than the adiabatic one $\mathrm{k}_{\mathrm{d}}$ ), one can obtain the actual expansion (z-d) characterized by a polytropic exponent $1<\mathrm{n}_{\mathrm{d}}<\mathrm{k}_{\mathrm{d}}$.

At the beginning all the temperatures and the pressures in the characteristic points of the thermodynamic cycle were calculated [3]. The burning efficiency, defined as the ratio between the heat transferred to the working fluid and the heat released by burning $1 \mathrm{~kg}$. of fuel, was also determined [3].

\section{The calculus of the technical-economic parameters}

The mechanical work developed by burning $1 \mathrm{~kg}$ of fuel:

$$
L_{M}=L_{r r_{1}}+L_{r_{1} a}-\left|L_{a c}\right|+L_{z u}+L_{u d}-\left|L_{d_{1 r} r}\right| \text {; }
$$

The mechanical work in the polytropic expansion of the residual burned gases, with constant isentropic exponent:

$$
L_{r r_{\mathrm{i}}}=\frac{p_{o} V_{s}}{1-\psi_{e}} \cdot \frac{1}{\varepsilon-1} \cdot \frac{1-\psi^{\frac{k_{e}-1}{k_{e}}}}{k_{e}-1} ;[\mathrm{J}]
$$

where: - $\mathrm{p}_{0}[\mathrm{~Pa}]$ - the environmental pressure;

$-\mathrm{V}_{\mathrm{s}}\left[\mathrm{m}^{3}\right]$ - the cylinder's displacement;

$-\psi_{\mathrm{e}}=\left(\mathrm{p}_{\mathrm{r}}-\mathrm{p}_{0}\right) / \mathrm{p}_{\mathrm{r}}-$ the coefficient of the exhaust pressure relative drop;

- $\varepsilon$ - the compression ratio;

$-\psi=\mathrm{p}_{\mathrm{a}} / \mathrm{p}_{\mathrm{r}}-$ the global coefficient of the pressure losses;

- $\mathrm{k}_{\mathrm{e}}$ - the mean adiabatic exponent of the exhaust process;

The mechanical work in the intake stroke:

$L_{r_{1} a}=p_{o} \cdot\left(1-\psi_{a}\right) \cdot V_{s} ;[\mathrm{J}]$

where: $-\psi_{\mathrm{a}}=\left(\mathrm{p}_{0}-\mathrm{p}_{\mathrm{a}}\right) / \mathrm{p}_{0}$ - the coefficient of the intake pressure relative drop;

The mechanical work in the compression process:

$\left|L_{a c}\right|=p_{o} V_{s}\left(1-\psi_{a}\right) \cdot \frac{\varepsilon^{n_{c}}}{\varepsilon-1} \cdot \frac{1-\varepsilon^{1-n_{c}}}{n_{c}-1} ;[\mathrm{J}]$

where: $-\mathrm{n}_{\mathrm{c}}$ - the polytropic exponent of the compression process;

The mechanical work in the afterburning process:

$$
L_{z u}=\beta \cdot p_{o} V_{s}\left(1-\psi_{a}\right) \cdot \frac{\varepsilon^{n_{c}}}{\varepsilon-1} \cdot \frac{1}{n_{u}-1} \cdot\left[1-\left(\frac{1}{\delta}\right)^{n_{u}-1}\right] ;[\mathrm{J}]
$$

where: $-\delta=\mathrm{V}_{\mathrm{u}} / \mathrm{V}_{\mathrm{z}}$ - the volume raise ratio in the afterburning process;

$-\mathrm{n}_{\mathrm{c}}$ - the polytropic exponent in the afterburning process;

$-\beta=p_{z} / p_{c}-$ the pressure raise ratio in the constant volume burning;

The mechanical work in the expansion process:

$$
L_{u d}=p_{o} V_{s}\left(1-\psi_{a}\right) \cdot \frac{\varepsilon^{n_{c}}}{\varepsilon-1} \cdot \beta \cdot \delta \cdot\left(\frac{1}{\delta}\right)^{n_{u}} \cdot \frac{1-\left(\frac{\delta}{\varepsilon}\right)^{n_{d}}}{n_{d}-1} ;[\mathrm{J}]
$$


where: - $\mathrm{n}_{\mathrm{d}}$-the polytropic exponent of the expansion process;

The mechanical work in the exhaust stroke:

$\left|L_{d_{1} r}\right|=\frac{p_{o}}{1-\psi_{e}} \cdot V_{s} ;[\mathrm{J}]$

The theoretical mechanical work developed by burning $1 \mathrm{~kg}$. of fuel:

$L_{M t}=\eta_{d} \cdot L_{M}[\mathrm{~J}]$

where: $-\eta_{\mathrm{d}}-\mathrm{a}$ correction coefficient of the indicated diagram that takes into consideration the effects of the simplifying assumptions;

The theoretical indicated mean pressure:

$p_{i t}=L_{M t} / V_{s} ;[\mathrm{J}]$

The theoretical efficiency [2]:

$\eta_{t}=\frac{L_{M t}}{\xi \cdot d \cdot \eta_{v} \cdot \rho_{o} \cdot V_{s} \cdot Q_{i}}$

where: $-\xi-$ a coefficient that specifies the proportion of the heat released during the burning process that's transferred to the working gas;

- $d$ - the air-fuel ratio;

- $\eta_{\mathrm{V}}-$ the volumetric efficiency [4];

- $\rho_{0}\left[\mathrm{~kg} / \mathrm{m}^{3}\right]$ - the air density in environmental conditions;

$-\mathrm{Q}_{\mathrm{i}}[\mathrm{J} / \mathrm{kg}]$ - the gross caloric power of the fuel;

The pressure losses due to the friction between the moving parts of the engine:

$\mathrm{p}_{\mathrm{mec}}=\mathrm{a}+\mathrm{b} \cdot \mathrm{W}_{\mathrm{pm}}[\mathrm{Pa}]$

where: - $a=0,21 ; b=0,037$ - coefficients of which values are taken from tables with formulas for the approximate calculus of the mean pressure and of the mechanical losses depending on the piston's mean speed [2], [5];

- $\mathrm{W}_{\mathrm{pm}}=\mathrm{S} \cdot \mathrm{n} / 30$ - the piston's mean speed ( $\mathrm{S}$ is the stroke and $\mathrm{n}$ is the rotational speed);

The theoretical mean effective pressure:

$\mathrm{p}_{\mathrm{et}}=\mathrm{p}_{\mathrm{it}}-\mathrm{p}_{\mathrm{mec}} \quad[\mathrm{Pa}]$

The engine's effective efficiency:

$\eta_{e}=\frac{p_{e t}}{\xi \cdot d \cdot \eta_{v} \cdot \rho_{o} \cdot Q_{i}}$

The theoretical effective power [5]:

$P_{t}=\frac{p_{e t} \cdot V_{s} \cdot i \cdot n}{30 \cdot v} ; \quad[\mathrm{kW}]$

where: $-\mathrm{i}=4-$ the number of cylinders;

$-v=4$ - the number of the piston's strokes in one engine cycle;

The effective engine's torque:

$\mathrm{M}_{\mathrm{e}}=9550 \cdot \mathrm{P}_{\mathrm{t}} / \mathrm{n} \quad[\mathrm{Nm}]$

The fuel mass injected in one engine cycle [6]:

$\mathrm{m}_{\mathrm{cb}}=10^{3} \cdot \xi \cdot \mathrm{d} \cdot \eta_{\mathrm{v}} \cdot \rho_{0} \cdot \mathrm{V}_{\mathrm{s}} \quad[\mathrm{g}]$

The hourly fuel consumption:

$C_{h}=120 \cdot \frac{m_{c b} \cdot i \cdot n}{v} ; \quad[\mathrm{g} / \mathrm{h}]$

The effective specific fuel consumption:

$\mathrm{c}_{\mathrm{e}}=\mathrm{C}_{\mathrm{h}} / \mathrm{P}_{\mathrm{e}} \quad[\mathrm{g} / \mathrm{KWh}]$ 
In Figure 3 is presented the variation of the fuel mass injected in one cycle $\mathrm{m}_{\mathrm{cb}}$, depending on the rotational speed and on the environmental temperature, for an air excess coefficient $\lambda=1$.

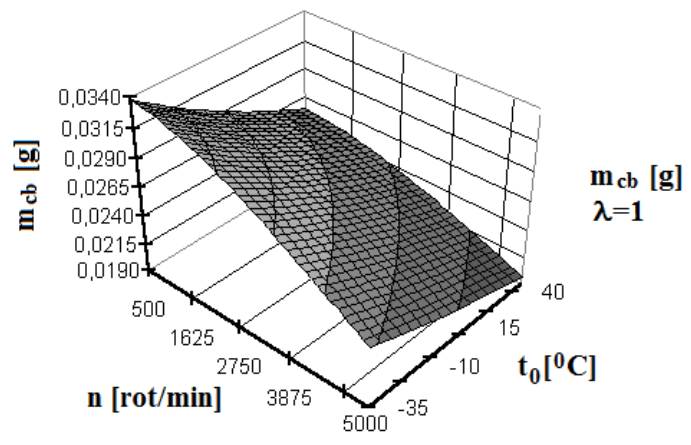

a.

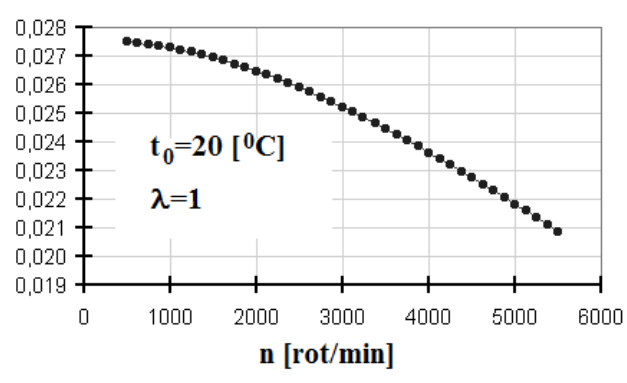

b.

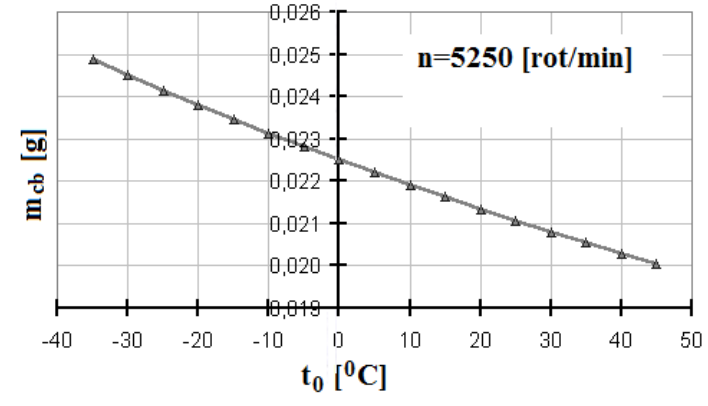

c.

Figure 3. The variation of the fuel mass injected in one engine cycle: a) depending on the rotational speed and on the environmental temperature; b) depending on the rotational speed; c) depending on the environmental temperature;

As shown in fig. 3b, the fuel mass injected during an engine cycle decreases as the environmental temperature increases. This is normal because, maintaining the same volume of injected fuel, the density decreases and so the mass also decreases. Also (see fig. 3c) the fuel mass injected during an engine cycle decreases as the rotational speed increases. This looks odd taking into consideration that the engine's power increases as the rotational speed increases. But again this is normal because also the number of engine's cycle in a given time increases with the rotational speed, so in the same time a greater amount of fuel is injected in the cylinder at higher rotational speeds.

In Figure 4 is presented the variation of the effective specific fuel consumption $c_{e}$, depending on the rotational speed and on the environmental temperature, for an air excess coefficient $\lambda=1$. 


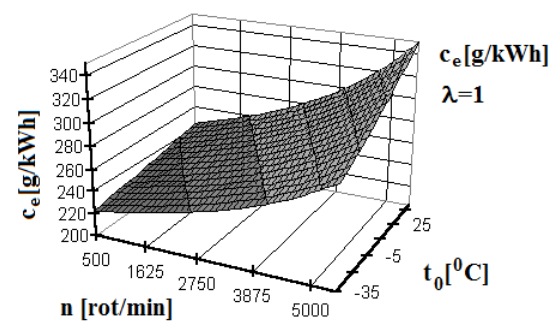

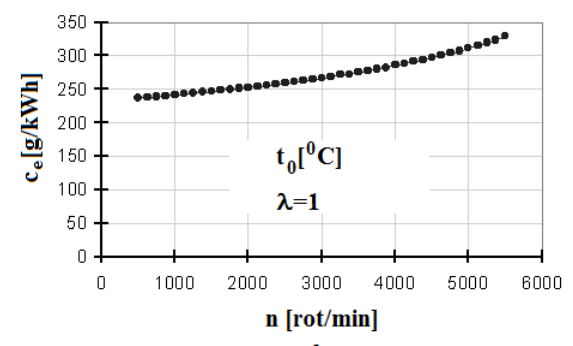

b.

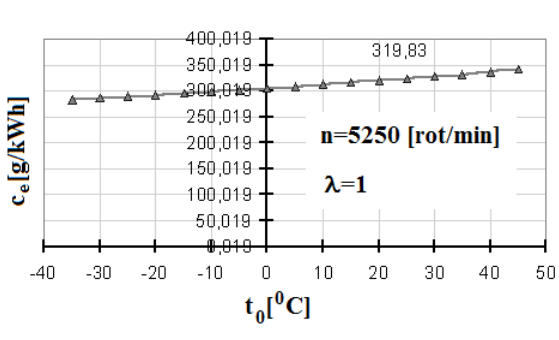

c.

Figure 4. The variation of the effective specific fuel consumption: a) depending on the rotational speed and on the environmental temperature; b) depending on the rotational speed;

c) depending on the environmental temperature;

The calculated indicated diagram is presented in Figure 5.

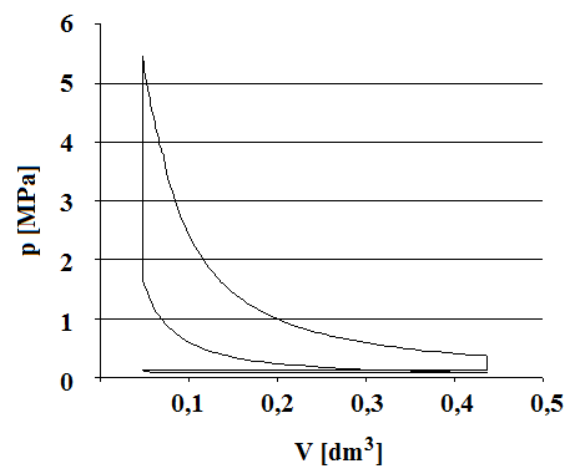

Figure 5. The calculated indicated diagram

These are all the engine's parameters that were determined with the proposed model.

\section{Conclusions}

In order to evaluate the accuracy of the proposed model, a comparison between calculated and experimental data for the effective specific consumption was made (Figure 6).

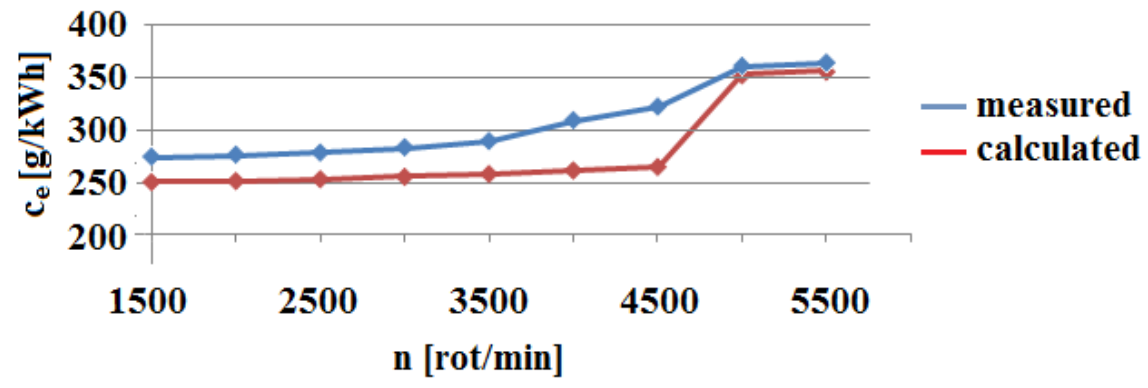

Figure 6. Comparison between calculated and experimental data for the effective specific fuel consumption 
The maximum differences are registered in the rotational speed interval $\mathrm{n}=4000-5000 \mathrm{rot} / \mathrm{min}$, with values between 18-21,5\%. At low rotational speeds the differences are of 9,3-11,84\%. Instead, at high rotational speeds the differences are only of 2,2-2,3\%.

So, one can observe that the model is fully applicable for full loads at rotational speeds close to the one of maximum power.

For medium and low rotational speeds the differences between the calculated and the experimental data are relatively great. This means that the model of the injection system must be improved.

The next studies should be focused on the calibration of the injection system model at low and medium rotational speeds and at partial loads.

At full load SI direct injection engines operate with stoichiometric mixtures and the fuel injection takes place during the intake stroke. It seems that the model developed by the authors covers very well this range of the engine's operation regime.

In return, at partial loads and low-medium rotational speeds, SI direct injections are operating with ultra lean mixtures that lead to a reduction of the fuel consumption and of the polluting emissions. In this case, after the closure of the intake valve, the injection can take place in multiple phases. This is a phenomenon hard to model.

Maybe, after some corrections, the model proposed in this article could be used to design new types of direct injection SI engines or to improve the existing ones.

\section{References}

[1] Vasile Blaga, Tudor Mitran, George Dragomir, Nicolae Chioreanu, The calculation of the injection process for an si engine with electromagnetic injectors, International Congress Science and Management of Automotive and Transportation Engineering SMAT 2014, Craiova, Tome 1, pp 59-62

[2] Radcenco Vs., Criteria for the optimization of the thermal processes (Criterii de optimizare a proceselor termice). Technical publishing ( Editura Tehnică), Bucharest (Bucureşti), 1977.

[3] Blaga V., Contributions to the modelling of the gasoline injection at SI engines (Contribuţii la modelarea injecţiei de benzină la motoare cu aprindere prin scânteie). $\mathrm{PhD}$ Thesis (Teză de doctorat). Technical University of Cluj-Napoca (Universitatea Tehnică Cluj-Napoca), Faculty of Mechanics (Facultatea de Mecanică), March , 2000.

[4] Tudor Mitran, Vasile Blaga, Sorin Moca, George Dragomir, Dinu Fodor, The calculation algorithm for the determination of the temperature at the end of the intake stroke for GDI engines; 12th International Congress of Automotive and Transport Engineering (CONAT), Brasov, 2016; pag. 311-318;

[5] Grünwald, B., Teoria, calculul şi construcţia motoarelor pentru autovehicule rutiere. Editura Didactică şi Pedagogică, Bucureşti, 1980.

[6] Băţagă, N. et al. Thermal Engines (Motoare termice). Didactic and Pedagogical Publishing (Editura Didactică şi Pedagogică), Bucharest (Bucureşti), 1979. 